\title{
Wheeze Recognition Algorithm for Remote Medical Care Device in Children: Validation Study
}

Chizu Habukawa ${ }^{1}$, MD, PhD; Naoto Ohgami ${ }^{2}$, MSc; Takahiko Arai ${ }^{3}, \mathrm{MD}$; Haruyuki Makata ${ }^{4}$, MD, PhD; Morimitsu Tomikawa ${ }^{5}$, MD; Tokihiko Fujino ${ }^{6}$, MD; Tetsuharu Manabe ${ }^{7}$, MD; Yoshihito Ogihara ${ }^{8}$, MD, PhD; Kiyotaka Ohtani ${ }^{9}$, MD, PhD; Kenichiro Shirao ${ }^{10}$, MD, PhD; Kazuko Sugai ${ }^{11}$, MD, PhD; Kei Asai ${ }^{2}$, BSc; Tetsuya Sato ${ }^{2}$, PhD; Katsumi Murakami $^{12}, \mathrm{MD}, \mathrm{PhD}$

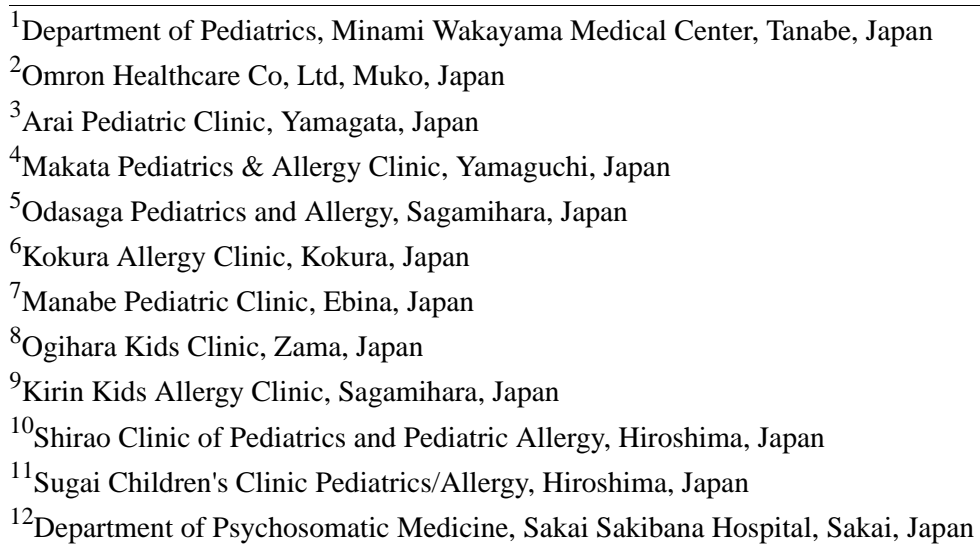

Corresponding Author:

Chizu Habukawa, MD, PhD

Department of Pediatrics

Minami Wakayama Medical Center

27-1 Takinai-machi

Tanabe, 646-0015

Japan

Phone: 81739267050

Fax: 81739242055

Email: gd6c-hbkw@asahi-net.or.jp

\section{Abstract}

Background: Since 2020, peoples' lifestyles have been largely changed due to the COVID-19 pandemic worldwide. In the medical field, although many patients prefer remote medical care, this prevents the physician from examining the patient directly; thus, it is important for patients to accurately convey their condition to the physician. Accordingly, remote medical care should be implemented and adaptable home medical devices are required. However, only a few highly accurate home medical devices are available for automatic wheeze detection as an exacerbation sign.

Objective: We developed a new handy home medical device with an automatic wheeze recognition algorithm, which is available for clinical use in noisy environments such as a pediatric consultation room or at home. Moreover, the examination time is only 30 seconds, since young children cannot endure a long examination time without crying or moving. The aim of this study was to validate the developed automatic wheeze recognition algorithm as a clinical medical device in children at different institutions.

Methods: A total of 374 children aged 4-107 months in pediatric consultation rooms of 10 institutions were enrolled in this study. All participants aged $\geq 6$ years were diagnosed with bronchial asthma and patients $\leq 5$ years had reported at least three episodes of wheezes. Wheezes were detected by auscultation with a stethoscope and recorded for 30 seconds using the wheeze recognition algorithm device (HWZ-1000T) developed based on wheeze characteristics following the Computerized Respiratory Sound Analysis guideline, where the dominant frequency and duration of a wheeze were $>100 \mathrm{~Hz}$ and $>100 \mathrm{~ms}$, respectively. Files containing recorded lung sounds were assessed by each specialist physician and divided into two groups: 177 designated as "wheeze" files and 197 as "no-wheeze" files. Wheeze recognitions were compared between specialist physicians who recorded 
lung sounds and those recorded using the wheeze recognition algorithm. We calculated the sensitivity, specificity, positive predictive value, and negative predictive value for all recorded sound files, and evaluated the influence of age and sex on the wheeze detection sensitivity.

Results: Detection of wheezes was not influenced by age and sex. In all files, wheezes were differentiated from noise using the wheeze recognition algorithm. The sensitivity, specificity, positive predictive value, and negative predictive value of the wheeze recognition algorithm were $96.6 \%, 98.5 \%, 98.3 \%$, and $97.0 \%$, respectively. Wheezes were automatically detected, and heartbeat sounds, voices, and crying were automatically identified as no-wheeze sounds by the wheeze recognition algorithm.

Conclusions: The wheeze recognition algorithm was verified to identify wheezing with high accuracy; therefore, it might be useful in the practical implementation of asthma management at home. Only a few home medical devices are available for automatic wheeze detection. The wheeze recognition algorithm was verified to identify wheezing with high accuracy and will be useful for wheezing management at home and in remote medical care.

(JMIR Pediatr Parent 2021;4(2):e28865) doi: $\underline{10.2196 / 28865}$

\section{KEYWORDS}

asthma; children; infant; wheezing; wheeze recognition algorithm; pediatrics; remote; medical devices; validation; home management; algorithm; detection; chronic illness

\section{Introduction}

Since 2020, people's lifestyle worldwide has been largely changed due to the COVID-19 pandemic. In the medical field, many patients are afraid to become infected with the virus in clinics and prefer remote medical care. In remote medical care, the physician cannot examine the patient directly, and therefore it is important for the patients to accurately convey their condition to the physician. Thus, remote medical care should be implemented, and adaptable home medical devices are required for this purpose.

Wheeze is the most important exacerbation sign in various respiratory diseases among all age groups [1-3]. Bronchial asthma is one of the typical diseases that requires home management, in which physicians detect wheezes by auscultation as acute exacerbation. Therefore, for the home management of asthma, caregivers should be aware of wheezing in small children at night and adolescents during play exercise. Moreover, physicians are mostly dependent on reports from family members and caregivers regarding symptoms, who may have different judgment criteria for wheezes [4-6]. Therefore, a high-accuracy objective method to detect wheezes would be beneficial for physicians and patients' families or caregivers. To the best of our knowledge, no appropriate home device has been used to detect wheezing as a mild exacerbation sign to date.

Computerized lung sound analysis, especially computerized wheeze detection, is a more objective and standardized method, which can overcome limitations of subjective auscultation $[3,7]$. In the medical field, technical innovation has engendered telemedicine and home-based therapy; however, the practical use of these technologies has been limited. For respiratory diseases, lung sounds represent simple physical data, which have no value by themselves and are only clinically important when evaluated with identical criteria of judgment by a physician [8-10].

For remote medical care, we developed a new handy home medical device with automatic wheeze recognition algorithms, which is available for clinical use in noisy environments such as a pediatric consultation room or at home. Moreover, the examination time is only 30 seconds because small children cannot endure long examination times without crying or moving [11]. In this study, we aimed to validate the automatic wheeze recognition algorithm based on wheeze sound characteristics with this new small handy device for clinical use in young children, including infants, at different institutions.

\section{Methods}

\section{Participants}

Ten institutions that have pediatric respiratory and allergy specialists were registered for this study. All participants were outpatient children attending the entry clinic and hospital located in Japan (Yamagata, Kanagawa, Hiroshima, Yamaguchi, Fukuoka, and Wakayama) between September 24, 2019 and November 22, 2019. All participants were brought into the hospital for the treatment of recurrent wheezes with cough and dyspnea. Written informed consent was obtained from all participants or their legal guardians. The study protocol was approved by the ethics committee of Minami Wakayama Medical Center [approval number 2016-22(5)]. All participants aged $\geq 6$ years were diagnosed with bronchial asthma, and their asthmatic severities were classified as mild asthma according to the 2017 Japanese Pediatric Guideline for the Treatment and Management of Asthma [12]. The children were treated with a leukotriene receptor antagonist and/or inhaled corticosteroid in accordance with the guidelines [12]. Participants aged $\leq 5$ years had reported at least three episodes of wheezes and had been treated with a leukotriene receptor antagonist or without medicine for long-term management.

\section{Study Procedures}

A specialist physician examined all participants using a stethoscope and simultaneously recorded lung sounds during tidal breathing in the pediatric consultation room for at least 30 seconds. Recordings were obtained from the upper right anterior chest region at the second intercostal space in the midclavicular line of the chest wall. Recorded lung sounds (with or without wheezes) were then listened to by the same specialist physician 
who recorded lung sounds, and then confirmed and classified the sounds in accordance with previous methods [11].

A total of 177 recordings were designated as "wheeze" files and 197 were designated as "no-wheeze" files. In addition, each specialist physician who recorded lung sounds differentiated wheezes from lung sound samples, including inspiratory and expiratory lung sounds, nasal congestion, crying, and voices.

\section{Sound Recording and Analysis}

\section{HWZ-1000T Device}

Lung sounds were recorded using a small handy device with an automatic wheeze recognition algorithm (HWZ-1000T, Omron Healthcare Corporation, Kyoto, Japan) (Figure 1a).
Two microphones are installed in the sensor unit, one for recording lung sounds and the other for recording environmental sounds. The microphone for recording lung sounds makes the judgment of wheezes through skin contact. Recorded lung sounds are processed using a wheezing recognition algorithm implemented in the internal central processing unit to automatically determine the presence or absence of wheezing, and then the results of wheezing judgment can be displayed on the device after 30 seconds. To analyze recorded wheeze sounds and compare judgment results by physicians who recorded wheezing with the automatic wheeze recognition algorithm, we attached a micro-SD memory card to the HWZ-1000 T device for confirmation of recorded lung sounds. The outline of the algorithm is described below.

Figure 1. Sound recording device and flowchart of the wheeze detection algorithm. FFT: fast Fourier transform.

a

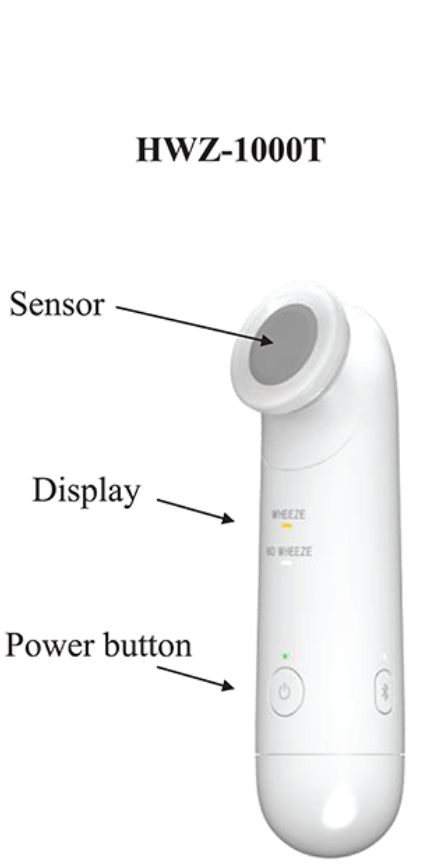

\section{b}

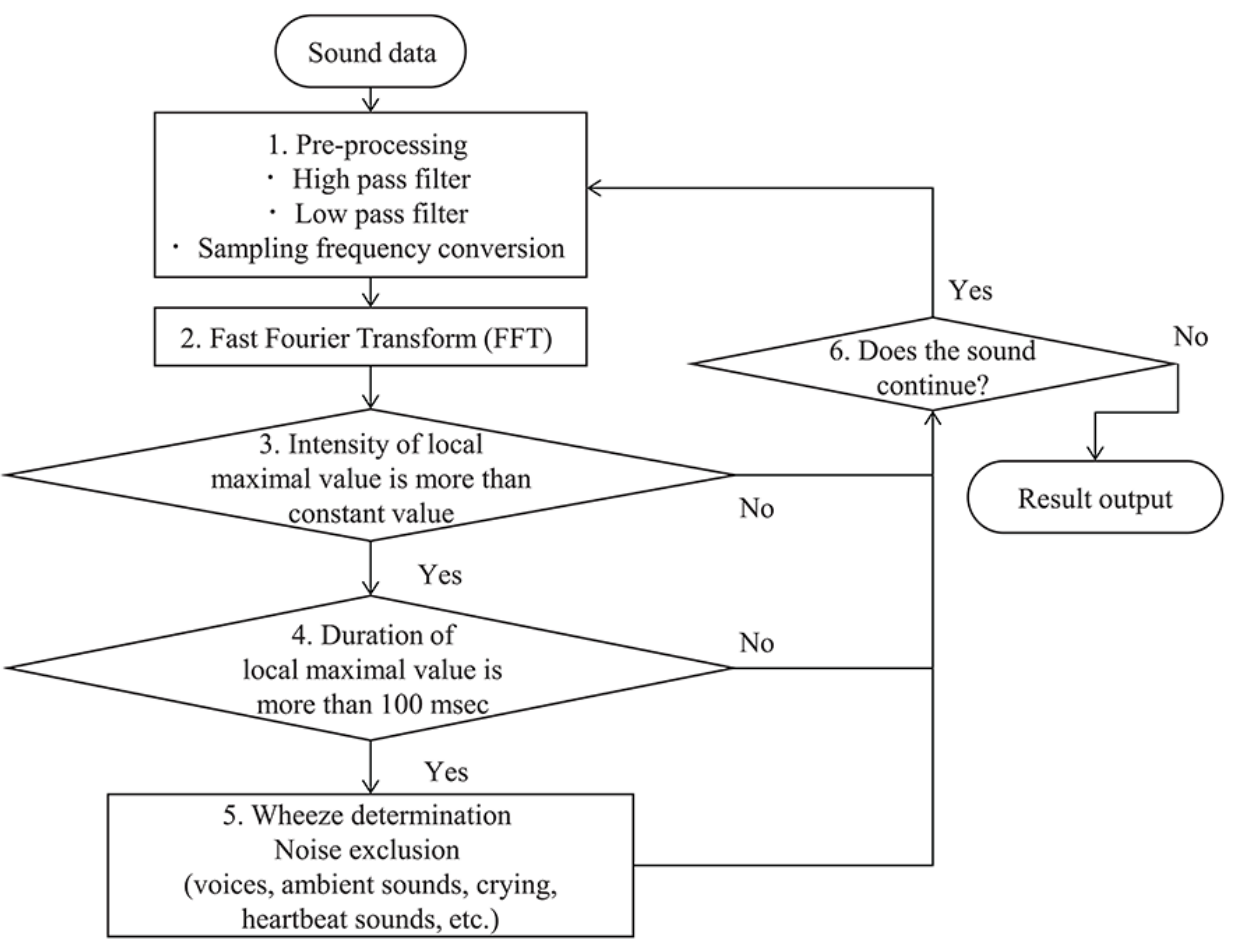

\section{Characteristics of Wheeze by Lung Sounds Analysis}

According to the Computerized Respiratory Sound Analysis guidelines, the dominant frequency and duration of a wheeze were set to $>100 \mathrm{~Hz}$ and $>100 \mathrm{~ms}$, respectively [13]. Furthermore, a previous report described the frequency range of a typical wheeze to be between 100 and $5000 \mathrm{~Hz}$ [1]. The maximum duration of a wheeze is within the expiratory duration. A wheeze detection algorithm was developed based on this definition.

Figure 2 (right panels) shows a typical wheeze spectrogram, with time (seconds) and frequency $(\mathrm{Hz})$ on the horizontal and vertical axes, respectively. The sound intensity $(\mathrm{dB})$ is shown as color and brightness. A continuous wheeze spectrum was created based on the lung sound analysis. On the left panels, horizontal axes show intensity $(\mathrm{dB})$ and the vertical axis shows frequency $(\mathrm{Hz})$. Wheeze sounds are shown as horizontal bars with intensity corresponding to peaks in the power spectrum display [1,13-15]. Wheeze sounds were classified into two types. On the left panel, a wheeze shows only one peak with intensity as a monophonic wheeze, and on the right panel, a wheeze shows many peaks with intensity as polyphonic wheezes. Wheezing is considered monophonic when only one pitch is heard, whereas it is considered polyphonic when multiple frequencies are simultaneously perceived. Polyphonic wheezing indicates more severe bronchial constriction than monophonic wheezing $[3,16,17]$. 
Figure 2. Monophonic and polyphonic wheezes. A: (a) Spectrum 1: Fast Fourier transform (FFT) frame, 21.000-21.372 s; (b) Spectrum 2: FFT frame, 21.018-21.390 s; (c) Spectrum 3: FFT frame, 21.036-21.408 s; (d) Spectrum 4: FFT frame, 21.054-21.426 s. B: (a) Spectrum 1: FFT frame, $25.000-25.372$ s; (b) Spectrum 2: FFT frame, 25.018-25.390 s; (c) Spectrum 3: FFT frame, 25.036-25.408 s; (d) Spectrum 4: FFT frame, 25.054-25.426.

a

(a)

(b)

Mono-phonic wheeze

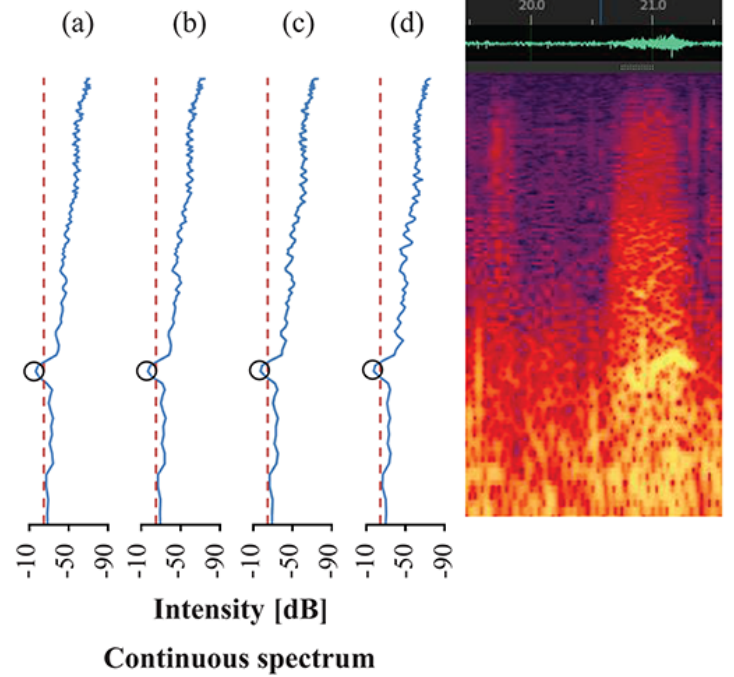

\section{Wheeze Recognition Algorithm}

Based on the definition of wheeze characteristics, a flowchart was created for the developed wheeze recognition algorithm from the sound collection to automatically detect wheezes to generate results. Details of the wheeze recognition algorithm were provided in our previous report [11] (Figure 1b). We describe the wheeze recognition algorithm with the following overall approach that consisted of five phases.

In step 1, sound data were preprocessed using high and low bandpass filters. Data were resampled at a sampling rate of $11.025 \mathrm{kHz}$ and at a 16-bit quantization rate.

In step 2, fast Fourier transform (FFT), the most well-known acoustic analysis method, was used. FFT analyzes the intensity for each frequency of sound data. The sound data were preprocessed using a hamming window of 4096 points (372 $\mathrm{ms}$ ), and processing was repeated every 128-point $(18 \mathrm{~ms})$ increase in the sound data [18-20].

Since the lung sound spectra had many local maximum points each time, in step 3, some local maximum points higher than the threshold were extracted as candidates for wheeze sounds. Black-circled points indicate the extracted local maximum points. The orange dotted line represents the threshold value used to determine the local maximum point. Threshold values were determined from overall sound pressure levels between 90 and $5000 \mathrm{~Hz}$.

In step 4, whether the local maximum points selected in step 3 continued for $>100 \mathrm{~ms}$ was determined according the definition of wheeze characteristics [13]. Continuous local maximum values selected in step 4 still included wheeze sounds and other noises, including voices, ambient sounds, crying, and heartbeat sounds.

In step 5, threshold values were determined using feature values to eliminate noises. To finally determine the presence of wheezes using both lung and ambient sounds, feature values of b

Poly-phonic wheezes

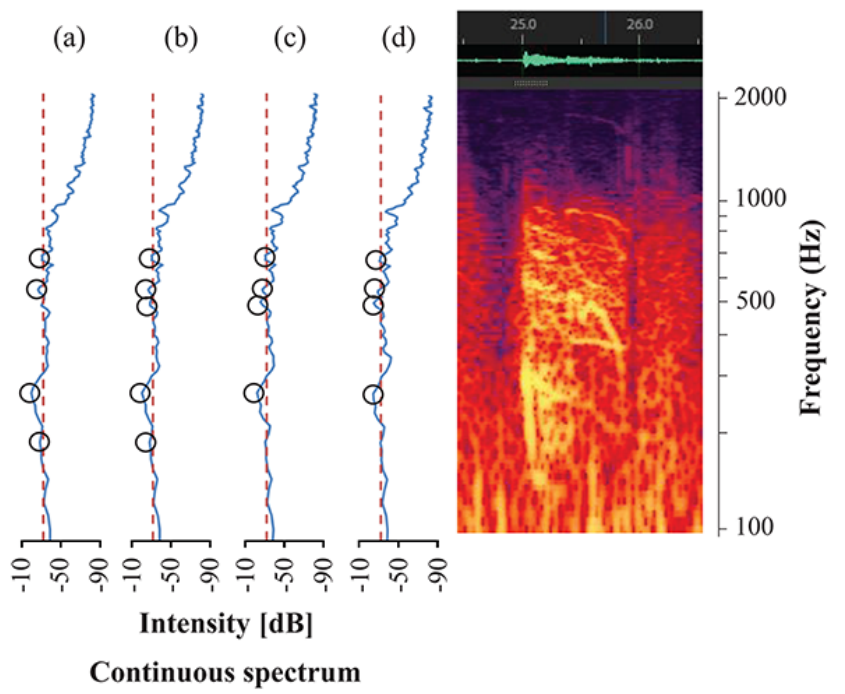

wheezing candidates selected in step 4 were calculated. Finally, if at least one wheeze sound was heard in a file, it was identified as a wheeze file, whereas if no wheeze sound was heard in a file, it was identified as a no-wheeze file.

For validation, we compared the judgment of wheeze sound recognition using the algorithm to assess all files that were discriminated by each specialist physician who recorded lung sounds.

\section{Statistical Analysis}

The results fell into one of the following four categories: actual positives that were correctly predicted as positives (true positives, TP); actual positives that were wrongly predicted as negatives (false negatives, FN); actual negatives that were correctly predicted as negatives (true negatives, $\mathrm{TN}$ ); and actual negatives that were wrongly predicted as positives (false positives, FP). We analyzed the sensitivity $(\mathrm{TP} / \mathrm{TP}+\mathrm{FN})$, specificity $(\mathrm{TN} / \mathrm{TN}+\mathrm{FP})$, positive predictive value $(\mathrm{PPV}=$ $\mathrm{TP} / \mathrm{TP}+\mathrm{FP})$, and negative predictive value $(\mathrm{NPV}=\mathrm{TN} / \mathrm{TN}+\mathrm{FN})$ using the wheeze recognition algorithm results in all data files $[21,22]$. PPV is defined as the probability that files identified as "wheeze" files by the specialists were also identified as "wheeze" files by the algorithm. NPV is the probability that files identified as "no-wheeze" files by the specialists were also identified as "no-wheeze" files by the algorithm.

Statistical analysis was performed using $\mathrm{R}$ software version 3.4.1. Patient characteristics are presented as the mean and range. Wheeze sound characteristics are presented as mean (SD) and range. Noise ratios in each sound discriminated by the algorithm are presented as a percentage of all noises. The relationship between age and sensitivity of wheeze recognition was analyzed using the Jonckheere-Terpstra test [23,24]. A $P$ value $<.05$ was considered statistically significant. 


\section{Results}

Table 1. Participant characteristics $(\mathrm{N}=374)$.

\begin{tabular}{ll}
\hline Characteristic & Value \\
\hline Age (months), mean (SD) & $44.3(31.6)$ \\
Age category (months), n (\%) & $54(14.4)$ \\
$4-11$ & $70(18.7)$ \\
$12-23$ & $52(13.9)$ \\
$24-35$ & $38(10.2)$ \\
$36-47$ & $48(12.8)$ \\
$48-59$ & $19(5.1)$ \\
$60-71$ & $18(4.8)$ \\
$72-83$ & $45(12.0)$ \\
$84-95$ & $30(8.0)$ \\
$96-107$ & \\
Sex, $\mathbf{n}(\boldsymbol{\%})$ & $241(64.4)$ \\
Male & $133(35.6)$ \\
Female & $96.2(28.5), 56.0-133.0$ \\
Height (cm), mean (SD), range & $15.6(6.8), 4.5-34.0$ \\
Weight (kg), mean (SD), range &
\end{tabular}

\section{Classification of Recorded Sounds and Wheeze Characteristics}

Table 2 shows the classification of recorded sounds in all lung sound samples and wheeze sound characteristics. If the wheeze

\section{Participant Characteristics}

Table 1 shows the participant characteristics. contained essentially a single frequency, it was classified as a monophonic wheeze, whereas it was classified as a polyphonic wheeze if it contained several frequencies [25].

Table 2. Classification of sounds in all recorded sound files $(\mathrm{N}=1201)$.

\begin{tabular}{ll}
\hline Sound classification & Value \\
\hline Characteristics of wheeze sounds, mean (SD), range & $321(178), 100-1600$ \\
Frequency (Hz) & $21.2(7.0), 5.0-45.0$ \\
Intensity (dB) & $331(220), 100-2538$ \\
Duration (ms) & \\
Type of wheeze sounds, $\mathbf{n}(\%)$ & $457(38.1)$ \\
Monophonic wheeze & $744(61.9)$ \\
Polyphonic wheeze & 1201 \\
Total & $108(19.4)$ \\
Noise, $\mathbf{n}(\boldsymbol{\%})$ & $155(27.8)$ \\
Nasal congestion & $294(52.8)$ \\
Physician's voice & 557 \\
Ambient crying or voice & \\
Total & \\
\hline
\end{tabular}

\section{Number of Local Maximum Points of Wheeze Sounds}

Table 3 shows the number of local maximum points of wheeze sounds, for a total of 1201 in all recorded sounds. Among these,

$457(38.1 \%)$ wheezes were found to have one local maximum point. In addition, $352(29.3 \%)$ wheezes had two local maximum points. Overall, $<3$ local maximum points accounted for $>67.4 \%$ of all wheeze sounds. 
Table 3. Number of local maximum points of wheeze sounds in all recorded sounds ( $N=1201)$.

\begin{tabular}{|c|c|c|}
\hline Number of local maximum points & \multicolumn{2}{|c|}{ Wheeze sounds, n (\%) } \\
\hline 1 & \multicolumn{2}{|l|}{$457(38.1)$} \\
\hline 2 & \multicolumn{2}{|l|}{$352(29.3)$} \\
\hline 3 & \multicolumn{2}{|l|}{$187(15.6)$} \\
\hline 4 & \multicolumn{2}{|l|}{$104(8.7)$} \\
\hline 5 & \multicolumn{2}{|l|}{$58(4.8)$} \\
\hline 6 & \multicolumn{2}{|l|}{$18(1.5)$} \\
\hline 7 & \multicolumn{2}{|l|}{$16(1.3)$} \\
\hline 8 & \multicolumn{2}{|l|}{$3(0.2)$} \\
\hline 9 & \multicolumn{2}{|l|}{$5(0.4)$} \\
\hline 10 & \multicolumn{2}{|l|}{$1(0.1)$} \\
\hline $\begin{array}{l}\text { Accuracy of Wheeze Recognition } \\
\text { Table } 4 \text { displays the wheeze recognition results using the wheeze } \\
\text { detection algorithm. The sensitivity, specificity, PPV, and NPV }\end{array}$ & \multicolumn{2}{|c|}{$\begin{array}{l}\text { for wheeze recognition in all data files were } 96.6 \%(171 / 177) \text {, } \\
98.5 \%(194 / 197), 98.3 \%(171 / 174) \text {, and } 97.0 \% \text { (194/200), } \\
\text { respectively. }\end{array}$} \\
\hline \multirow[t]{2}{*}{ Identification by the algorithm } & \multicolumn{2}{|c|}{ Specialist's diagnosis by stethoscope } \\
\hline & Wheeze sound & No-wheeze sound \\
\hline Wheeze sound & $\mathrm{TP}^{\mathrm{a}}=171$ & $\mathrm{FP}^{\mathrm{b}}=3$ \\
\hline No-wheeze sound & $\mathrm{FN}^{\mathrm{c}}=6$ & $\mathrm{TN}^{\mathrm{d}}=194$ \\
\hline
\end{tabular}

${ }^{\mathrm{a}} \mathrm{TP}:$ true positive.

${ }^{\mathrm{b}} \mathrm{FP}$ : false positive.

${ }^{\mathrm{c}} \mathrm{FN}$ : false negative.

${ }^{\mathrm{d}} \mathrm{TN}$ : true negative.

\section{Influence of Age and Sex on the Sensitivity of Wheeze \\ Detection}

The sensitivity and specificity of wheeze detection are shown in Table 5. The sensitivity and specificity of wheeze detection were not influenced by age and sex. 
Table 5. Influence of age and sex on the sensitivity of wheeze detection.

\begin{tabular}{|c|c|c|c|c|c|c|}
\hline \multirow[t]{2}{*}{ Group } & \multicolumn{3}{|c|}{ Wheeze data } & \multicolumn{3}{|c|}{ No-wheeze data } \\
\hline & $\mathrm{N}$ & $\mathrm{TP}^{\mathrm{a}}$ & Sensitivity (\%) (95\% CI) & $\mathrm{N}$ & $\mathrm{TN}^{\mathrm{b}}$ & Specificity (\%) $(95 \% \mathrm{CI})$ \\
\hline \multicolumn{7}{|c|}{ Age (months) } \\
\hline 0 & 24 & 23 & $95.8(78.9-99.9)$ & 30 & 28 & $93.3(77.9-99.2)$ \\
\hline 1 & 45 & 43 & $95.6(84.9-99.5)$ & 25 & 25 & $100(86.3-100)$ \\
\hline 2 & 27 & 26 & $96.3(81.0-99.9)$ & 25 & 25 & $100(86.3-100)$ \\
\hline $3-8$ & 81 & 79 & $97.5(91.4-99.7)$ & 117 & 116 & $99.1(95.3-100)$ \\
\hline \multicolumn{7}{|l|}{ Sex } \\
\hline Male & 110 & 106 & $96.4(89.3-97.6)$ & 131 & 130 & $99.2(92.2-98.6)$ \\
\hline Female & 67 & 65 & $97.0(90.3-99.3)$ & 66 & 64 & $97.0(88.6-98.3)$ \\
\hline Total & 177 & 171 & $96.6(92.8-98.7)$ & 197 & 194 & $98.5(95.6-99.7)$ \\
\hline
\end{tabular}

${ }^{\mathrm{a}} \mathrm{TP}$ : true positive.

${ }^{\mathrm{TN}} \mathrm{N}$ : true negative.

\section{Automatic Differentiation of Wheezes From Other Sounds Using the Wheeze Detection Algorithm}

Figure 3 a shows the wheeze recognition results with wheezing before inhalation. Wheezes (white squares) were accurately detected by the automatic recognition algorithm. Figure $3 \mathrm{~b}$ shows the no-wheeze results after inhalation, including crying and voices (arrows). The other noises were effectively discriminated from wheeze sounds; wheezes were automatically detected, whereas heartbeat sounds, voices, and crying were automatically identified as no-wheeze sounds by the wheeze recognition algorithm.

Figure 3. Results of wheeze recognition with wheezing before and after inhalation.
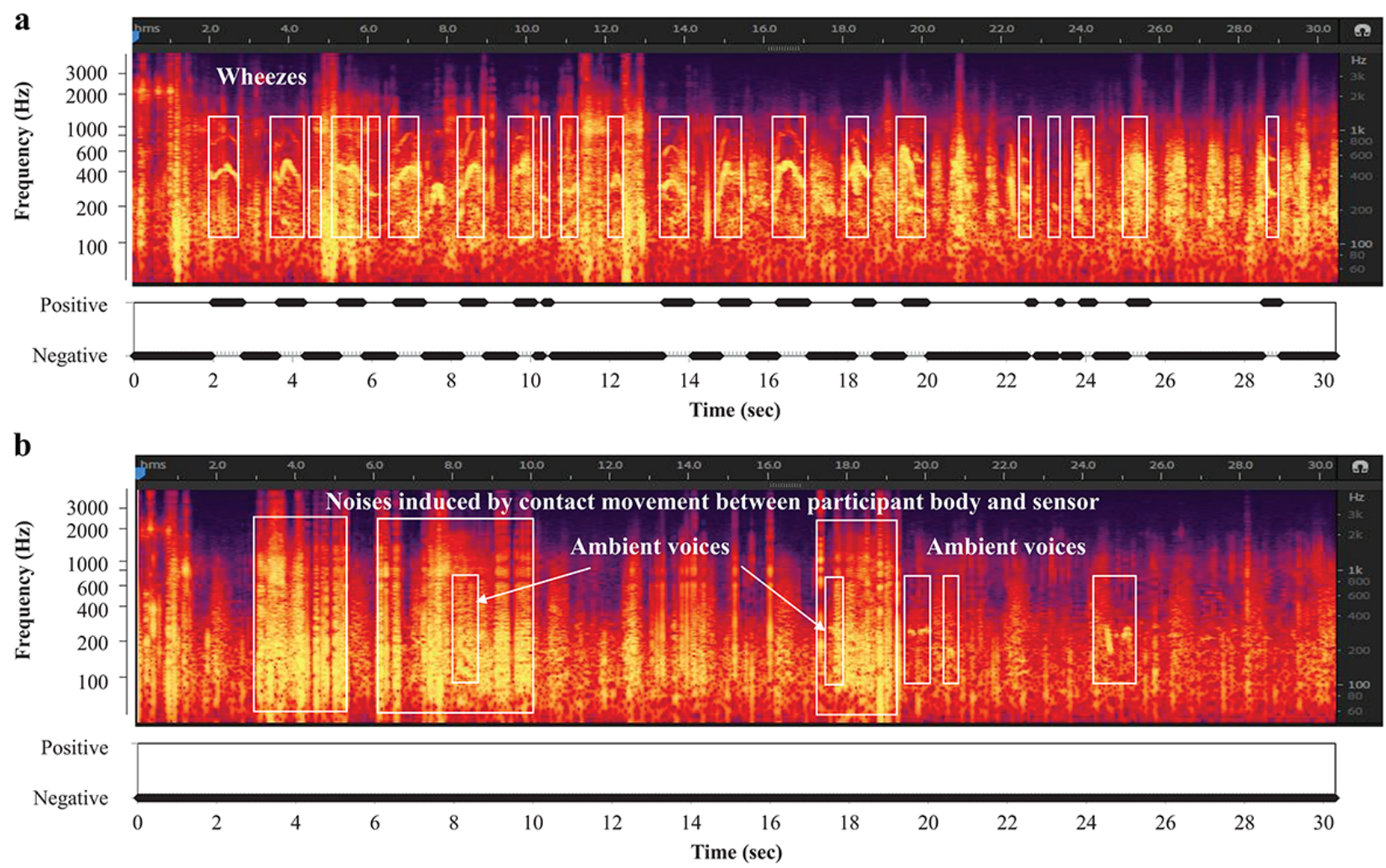

\section{Discussion}

Wheezes in children, including infants, were successfully detected using the newly developed small handy device with a wheeze recognition algorithm. This algorithm could precisely discriminate wheezes from other noises in an environment with various sounds. Furthermore, based on wheeze characteristics, the automatic wheeze recognition algorithm could detect even mild wheezes in crying infants recorded for 30 seconds in a pediatric consultation room. Therefore, we have successfully developed a real-time wheeze detection system with higher robustness for clinical use. 
Studies on automated wheeze detection have been performed for various clinical conditions $[17,18]$. These detection systems have been developed in the past three decades. In 1995, Gavriely [13] published the details of a technological approach for automated digital data acquisition and breathing sound processing. This commercial device, PulmoTrack, enabled automated and continuous wheeze monitoring. Boner et al [20] reported that monitoring wheezes during sleep was useful when treating children with asthma, and that the duration of wheezes during the recording was correlated with peak expiratory flow rate changes. Therefore, automated wheeze detection may be useful for the management of children with wheezes, especially infants. A meta-analysis found that computerized lung sound analysis had relatively high sensitivity and specificity in a small number of studies [26,27]. Although wheeze detection systems have been successfully implemented, they have not been used clinically in children (including infants), owing to several problems that can be encountered while using automated wheeze detection systems [28-30].

One important factor is the varied wheeze intensities among children. Wheezes are continuous adventitious lung sounds that are superimposed on breath sounds. According to new definitions in the current Computerized Respiratory Sound Analysis guidelines, the dominant frequency of a wheeze is usually $>100 \mathrm{~Hz}$ with a duration of $>100 \mathrm{~ms}$ [25]. The most common features of detecting wheezes are the use of different wheeze peak shapes in the time-frequency plane, such as amplitude spectrum, continuity, spread, sparseness, and kurtosis. Continuous local maximum points of intensity in the spectra, which are considered as the most common features associated with wheezes during lung analysis, were analyzed. Wheeze spectra and spectrograms have many local maximum points when using FFT. Other technologies such as PulmoTrack provide respiratory rates, inspiratory/expiratory time ratios, wheeze rate during the recording duration, and wheeze duration. PulmoTrack detected $>3$ local maximum points. However, <3 local maximum points accounted for $>67.4 \%$ of all wheeze sounds in this study and in our previous study, and our wheeze recognition algorithm could detect $>1$ local maximum point. Moreover, our algorithm could also detect mild wheezes [11].

Prodhan et al [31] used PulmoTrack in a pediatric intensive care unit and reported that wheeze detection was more accurate compared with that performed by hospital staff. Nurses' judgment of wheezing has been reported to differ from that of physicians and caregivers by nearly $60 \%$ [4]. The judgment of wheezing may also differ among each physician, which could be due to the variety of wheezing sounds and many local maximum points from a few weak local maximum points. In this verification study, although 10 specialists who recoded wheezing performed independent assessments, we succeeded in obtaining highly accurate results of wheezing judgment. In other words, our developed wheeze recognition algorithm can accurately detect weak and mild wheezing, which may be judged differently by specialists. Consequently, our algorithm exhibited higher sensitivity over other wheeze detection technologies.

Another problem to be overcome is that a short examination time is required to accurately detect wheezes, and a simple procedure should be clinically used in small children. In small children, including infants, recording lung sounds without crying, moving, or being distracted by the attached adhesive pads or belt is difficult. Therefore, we selected a method that can record within a 30-second period by attaching a microphone to the chest wall by hand. In a previous study on 214 children, including 30 infants, the sensitivity of wheeze detection using our algorithm was not affected by age [12]. Moreover, this study comprising 374 children, including 54 infants, showed that the sensitivity of wheeze detection using our algorithm was not affected by age or sex. In addition, the small handy device is useful size for children and their caregivers.

A highly precise noise-canceling technology should be developed for clinical use for young children. Recording lung sounds in a noisy clinic requires more rigorous postprocessing than recording in a quiet room to compensate for the noise present in the acoustic signal. Therefore, the efficiency of classification algorithms may differ. These inconsistencies would lead to difficulties in interpreting and translating study outcomes, and they have hindered the clinical use of computerized lung sound analysis devices, especially in children [25]. To improve the accuracy of the algorithm for automatically detecting wheezing, various methods have been developed with the aim of eliminating the influence of human voices and various environmental sounds, but they have not been put into practical use [32-34].

Algorithms such as neural networks, vector quantization, Gaussian mixture model classification systems, and support vector machines have been used to analyze spectral features. A support vector machine is a supervised machine-learning algorithm used for both classification and regression [28,29]. The presence of wheezes can be identified using a decision tree with classifiers of other noises. The decision tree is a method that can classify sounds according to detailed differences in sound features. Heartbeat sounds typically last for $<100 \mathrm{~ms}$. Voices and other sounds produce noises of higher decibel levels on the environmental microphone than wheezes on the lung sound microphone. Crying is louder on the lung sound microphone than on the environment microphone, but shows different continuous pattern ranges compared with wheeze sounds. Therefore, no-wheeze sounds could be automatically distinguished from wheezes using the wheeze detection algorithm. We discriminated wheezes from environmental noise based on different wheeze sound characteristics. Thus, no-wheeze sounds could be automatically distinguished from other noises in a noisy pediatric consultation room.

This study has a few limitations. First, the use of the algorithm at home should have been validated. Second, in case of severe airway obstruction, it did not demonstrate any audible lung sounds (known as "silent chest"); however, patients with a severe condition show a pale face or difficulty breathing. Therefore, caregivers can easily recognize these as exacerbation signs.

Wheezing often occurs in the absence of a doctor, such as during the night, at home, or during exercise, and possibly even in the absence of a parent. Our new home medical device, equipped with a highly accurate algorithm that is not affected by environmental noise, can easily detect wheezing and may be 
able to properly detect asthma attacks at home in the absence of a doctor, which will further be useful for remote medical care.

We successfully developed a real-time wheeze detection system with higher robustness for clinical application using lung sound analysis in children and infants. We successfully discriminated wheezes from other noises such as heartbeats, voices, and crying using the wheeze detection algorithm in a noisy pediatric consultation room. This practical implementation may provide beneficial information for physicians and parents of children and infants. In the future, we plan to verify whether use of this device can be expanded to include older children and adults. We hope to use the novel home medical device equipped with this algorithm, which could help improve the safety of children with asthma and respiratory illnesses.

\section{Acknowledgments}

The authors express their immense gratitude to the children and parents who consented to participate in this study. This study was supported by Omron Healthcare Co, Ltd.

\section{Conflicts of Interest}

NO, KA, and TS are employees of Omron Healthcare Co, Ltd. CH and KM received financial support from Omron Healthcare. The other authors have no conflicts to declare.

\section{References}

1. Meslier N, Charbonneau G, Racineux J. Wheezes. Eur Respir J 1995 Nov;8(11):1942-1948 [FREE Full text] [doi: 10.1183/09031936.95.08111942] [Medline: $\underline{\text { 8620967] }}$

2. Murphy R. In defense of the stethoscope. Respir Care 2008 Mar;53(3):355-369 [FREE Full text] [Medline: 18291053 ]

3. Forgacs P. The functional basis of pulmonary sounds. Chest 1978 Mar;73(3):399-405. [doi: 10.1378/chest.73.3.399] [Medline: 630938]

4. Cane RS, Ranganathan SC, McKenzie SA. What do parents of wheezy children understand by "wheeze"? Arch Dis Child 2000 Apr;82(4):327-332 [FREE Full text] [doi: 10.1136/adc.82.4.327] [Medline: 10735844]

5. Brand P, Baraldi E, Bisgaard H, Boner A, Castro-Rodriguez J, Custovic A, et al. Definition, assessment and treatment of wheezing disorders in preschool children: an evidence-based approach. Eur Respir J 2008 Oct;32(4):1096-1110 [FREE Full text] [doi: 10.1183/09031936.00002108] [Medline: 18827155$]$

6. Peterson-Carmichael S, Rosenfeld M, Ascher S, Hornik C, Arets H, Davis S, et al. Survey of clinical infant lung function testing practices. Pediatr Pulmonol 2014 Feb;49(2):126-131. [doi: 10.1002/ppul.22807] [Medline: 23765632]

7. Beck R, Elias N, Shoval S, Tov N, Talmon G, Godfrey S, et al. Computerized acoustic assessment of treatment efficacy of nebulized epinephrine and albuterol in RSV bronchiolitis. BMC Pediatr 2007 Jun 02;7:22 [FREE Full text] [doi: 10.1186/1471-2431-7-22] [Medline: 17543129$]$

8. Aliverti A. Wearable technology: role in respiratory health and disease. Breathe (Sheff) 2017 Jun;13(2):e27-e36 [FREE Full text] [doi: 10.1183/20734735.008417] [Medline: 28966692]

9. Zhang J, Ser W, Yu J, Zhang T. A novel wheeze detection method for wearable monitoring systems. 2009 May 15 Presented at: International Symposium on Intelligent Ubiquitous Computing and Education; 2009; Chengdu, China p. 331-334. [doi: 10.1109/IUCE.20066]

10. Taplidou S, Hadjileontiadis L, Kitsas I, Panoulas K, Penzel T, Gross V, et al. On applying continuous wavelet transform in wheeze analysis. Conf Proc IEEE Eng Med Biol Soc 2004;2004:3832-3835. [doi: 10.1109/IEMBS.2004.1404073] [Medline: 17271131]

11. Habukawa C, Ohgami N, Matsumoto N, Hashino K, Asai K, Sato T, et al. A wheeze recognition algorithm for practical implementation in children. PLoS One 2020;15(10):e0240048 [FREE Full text] [doi: 10.1371/journal.pone.0240048] [Medline: $\underline{33031408]}$

12. Arakawa H, Hamasaki Y, Kohno Y, Ebisawa M, Kondo N, Nishima S, Japanese Society of Pediatric Allergy Clinical Immunology, The Japanese Society of Allergology. Japanese guidelines for childhood asthma 2017. Allergol Int 2017 Apr;66(2):190-204 [FREE Full text] [doi: 10.1016/j.alit.2016.11.003] [Medline: 28108245]

13. Sovijarvi A, Vanderschoot J, Earis J. Standardization of computerized respiratory sound analysis. Eur Respir Rev 2000;10:585 [FREE Full text]

14. Elphick H, Ritson S, Rodgers H, Everard M. When a "wheeze" is not a wheeze: acoustic analysis of breath sounds in infants. Eur Respir J 2000 Oct;16(4):593-597 [FREE Full text] [doi: 10.1034/j.1399-3003.2000.16d04.x] [Medline: 11106197]

15. Jin F, Krishnan S, Sattar F. Adventitious sounds identification and extraction using temporal-spectral dominance-based features. IEEE Trans Biomed Eng 2011 Nov;58(11):3078-3087. [doi: 10.1109/tbme.2011.2160721]

16. Shim C. Relationship of wheezing to the severity of obstruction in asthma. Arch Intern Med 1983 May 01;143(5):890-892. [doi: 10.1001/archinte.1983.00350050044009]

17. Baughman R, Loudon R. Quantitation of wheezing in acute asthma. Chest 1984 Nov;86(5):718-722. [doi:

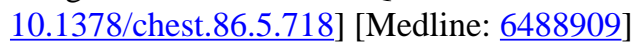


18. Taplidou S, Hadjileontiadis L. Wheeze detection based on time-frequency analysis of breath sounds. Comput Biol Med 2007 Aug;37(8):1073-1083. [doi: 10.1016/j.compbiomed.2006.09.007] [Medline: 17113064]

19. Yoshimasu T, Kawago M, Hirai Y, Ohashi T, Tanaka Y, Oura S, et al. Fast Fourier transform analysis of pulmonary nodules on computed tomography images from patients with lung cancer. Ann Thorac Cardiovasc Surg 2015;21(1):1-7 [FREE Full text] [doi: 10.5761/atcs.oa.13-00318] [Medline: 24583708]

20. Bentur L, Beck R, Shinawi M, Naveh T, Gavriely N. Wheeze monitoring in children for assessment of nocturnal asthma and response to therapy. Eur Respir J 2003 Apr;21(4):621-626 [FREE Full text] [doi: 10.1183/09031936.03.00036302] [Medline: 12762346]

21. Chicco D, Jurman G. The advantages of the Matthews correlation coefficient (MCC) over F1 score and accuracy in binary classification evaluation. BMC Genomics 2020 Jan 02;21(1):6 [FREE Full text] [doi: 10.1186/s12864-019-6413-7] [Medline: 31898477]

22. Rao G. Remembering the meanings of sensitivity, specificity, and predictive values. J Fam Pract 2004 Jan;53(1):53. [Medline: 14709268]

23. Wisniewski J, Agrawal R, Minnicozzi S, Xin W, Patrie J, Heymann P, et al. Sensitization to food and inhalant allergens in relation to age and wheeze among children with atopic dermatitis. Clin Exp Allergy 2013 Oct;43(10):1160-1170 [FREE Full text] [doi: 10.1111/cea.12169] [Medline: 24074334]

24. Hashizume H, Konno S, Takeshita K, Fukui M, Takahashi K, Chiba K, et al. Japanese orthopaedic association back pain evaluation questionnaire (JOABPEQ) as an outcome measure for patients with low back pain: reference values in healthy volunteers. J Orthop Sci 2015 Mar;20(2):264-280 [FREE Full text] [doi: 10.1007/s00776-014-0693-1] [Medline: 25687654]

25. Godfrey S, Uwyyed K, Springer C, Avital A. Is clinical wheezing reliable as the endpoint for bronchial challenges in preschool children? Pediatr Pulmonol 2004 Mar;37(3):193-200. [doi: 10.1002/ppul.10434] [Medline: 14966812]

26. Dellinger R, Parrillo J, Kushnir A, Rossi M, Kushnir I. Dynamic visualization of lung sounds with a vibration response device: a case series. Respiration 2008;75(1):60-72. [doi: 10.1159/000103558] [Medline: 17551264]

27. Andrès E, Reichert S, Gass R, Brandt C. A French national research project to the creation of an auscultation's school: the ASAP project. Eur J Intern Med 2009 May;20(3):323-327. [doi: 10.1016/j.ejim.2008.08.013] [Medline: 19393502]

28. Shaharum S, Sundaraj K, Palaniappan R. A survey on automated wheeze detection systems for asthmatic patients. Bosn J Basic Med Sci 2012 Nov;12(4):249-255. [doi: 10.17305/bjbms.2012.2447] [Medline: 23198941]

29. Cortes C, Vapnik V. Support-vector networks. Mach Learn 1995 Sep;20(3):273-297. [doi: 10.1007/bf00994018]

30. Gurung A, Scrafford C, Tielsch J, Levine O, Checkley W. Computerized lung sound analysis as diagnostic aid for the detection of abnormal lung sounds: a systematic review and meta-analysis. Respir Med 2011 Sep;105(9):1396-1403 [FREE Full text] [doi: 10.1016/j.rmed.2011.05.007] [Medline: 21676606]

31. Prodhan P, Dela Rosa RS, Shubina M, Haver K, Matthews B, Buck S, et al. Wheeze detection in the pediatric intensive care unit: comparison among physician, nurses, respiratory therapists, and a computerized respiratory sound monitor. Respir Care 2008 Oct;53(10):1304-1309 [FREE Full text] [Medline: 18811991]

32. Li S, Lin B, Tsai C, Yang C, Lin B. Design of Wearable Breathing Sound Monitoring System for Real-Time Wheeze Detection. Sensors (Basel) 2017 Jan 17;17(1):171 [FREE Full text] [doi: 10.3390/s17010171] [Medline: 28106747]

33. Andrès E, Gass R, Charloux A, Brandt C, Hentzler A. Respiratory sound analysis in the era of evidence-based medicine and the world of medicine 2.0. J Med Life 2018;11(2):89-106 [FREE Full text] [Medline: 30140315 ]

34. Puder L, Wilitzki S, Bührer C, Fischer H, Schmalisch G. Computerized wheeze detection in young infants: comparison of signals from tracheal and chest wall sensors. Physiol Meas 2016 Dec;37(12):2170-2180. [doi: 10.1088/0967-3334/37/12/2170] [Medline: 27869106]

\section{Abbreviations}

FFT: fast Fourier transform

FN: false negative

FP: false positive

NPV: negative predictive value

PPV: positive predictive value

TN: true negative

TP: true positive 
Edited by S Badawy, MD, MS, G Eysenbach; submitted 17.03.21; peer-reviewed by Y Nagasaka; comments to author 09.04.21; revised version received 16.04.21; accepted 16.04.21; published 17.06.21

Please cite as:

Habukawa C, Ohgami N, Arai T, Makata H, Tomikawa M, Fujino T, Manabe T, Ogihara Y, Ohtani K, Shirao K, Sugai K, Asai K, Sato T, Murakami K

Wheeze Recognition Algorithm for Remote Medical Care Device in Children: Validation Study

JMIR Pediatr Parent 2021;4(2):e28865

URL: https://pediatrics.jmir.org/2021/2/e28865

doi: $\underline{10.2196 / 28865}$

PMID: 33875413

(C)Chizu Habukawa, Naoto Ohgami, Takahiko Arai, Haruyuki Makata, Morimitsu Tomikawa, Tokihiko Fujino, Tetsuharu Manabe, Yoshihito Ogihara, Kiyotaka Ohtani, Kenichiro Shirao, Kazuko Sugai, Kei Asai, Tetsuya Sato, Katsumi Murakami. Originally published in JMIR Pediatrics and Parenting (https://pediatrics.jmir.org), 17.06.2021. This is an open-access article distributed under the terms of the Creative Commons Attribution License (https://creativecommons.org/licenses/by/4.0/), which permits unrestricted use, distribution, and reproduction in any medium, provided the original work, first published in JMIR Pediatrics and Parenting, is properly cited. The complete bibliographic information, a link to the original publication on https://pediatrics.jmir.org, as well as this copyright and license information must be included. 